\title{
Global ship accidents and ocean swell-related sea states
}

\author{
Zhiwei Zhang ${ }^{1,2}$ and Xiao-Ming $\mathbf{L i}^{3,4}$ \\ ${ }^{1}$ East Sea Information Center, State Oceanic Administration, Shanghai, China \\ ${ }^{2}$ College of Geography and Environment, Shandong Normal University, Jinan, China \\ ${ }^{3}$ Key Laboratory of Digital Earth Science, Institute of Remote Sensing and Digital Earth, \\ Chinese Academy of Sciences, Beijing, China \\ ${ }^{4}$ Hainan Key Laboratory of Earth Observation, Sanya, China \\ Correspondence to: Xiao-Ming Li (lixm@radi.ac.cn)
}

Received: 12 April 2017 - Discussion started: 26 April 2017

Revised: 4 September 2017 - Accepted: 16 October 2017 - Published: 28 November 2017

\begin{abstract}
With the increased frequency of shipping activities, navigation safety has become a major concern, especially when economic losses, human casualties and environmental issues are considered. As a contributing factor, the sea state plays a significant role in shipping safety. However, the types of dangerous sea states that trigger serious shipping accidents are not well understood. To address this issue, we analyzed the sea state characteristics during ship accidents that occurred in poor weather or heavy seas based on a 10-year ship accident dataset. Sea state parameters of a numerical wave model, i.e., significant wave height, mean wave period and mean wave direction, were analyzed for the selected ship accident cases. The results indicated that complex sea states with the co-occurrence of wind sea and swell conditions represent threats to sailing vessels, especially when these conditions include similar wave periods and oblique wave directions.
\end{abstract}

\section{Introduction}

The shipping industry delivers $90 \%$ of all world trade. It is currently a thriving business that has experienced increases in both the number and size of ships. However, due to the frequency of shipping activities, ship accidents have become a growing concern, as have the associated destructive consequences, including casualties, economic losses and various types of environmental pollution.

Investigations into the causes of shipping accidents show that over $30 \%$ of the accidents are caused by poor weather, and an additional $25 \%$ remain completely unexplained
(Faulkner, 2004). Due to these dangerous uncertainties, accidents that involve poor weather and severe sea states should be further studied for shipping safety.

However, under changing weather conditions, the sea surface is too complex to predict, especially on short timescales (Kharif et al., 2009). The sea surface is composed of random waves of various heights, lengths and periods. Meanwhile, different kinds of waves emerge frequently; among them, wind sea and swells are the two main types of ocean waves classified by wave generation mechanisms. Wind sea waves are directly generated by local winds, and when windgenerated waves propagate without receiving further energy from wind they transition into swells.

Meteorologists and oceanographers generally work with statistical parameters, such as the significant wave height $\left(H_{\mathrm{s}}\right)$, wave period ( $T$, zero-crossing period) and wave direction $(D)$, to represent a given sea state. Additionally, the wave spectrum, i.e., the distribution of wave energy among different wave frequencies $(f, f=1 / T)$, is analyzed in some studies to better understand wave dynamics. Note that a typical ocean wave spectrum with two peaks (e.g., one from distal swells and the other generated by the local wind) is much more complicated and variable.

In terms of the sea state parameters, $H_{\mathrm{s}}$ is usually a practical indicator of the sea state during marine activities. Indeed, some studies, such as an analysis of ship accidents that occurred in the North Atlantic region (Guedes et al., 2001), have shown that accident areas coincide with the zones with the highest $H_{\mathrm{s}}$. A high wave height is undoubtedly a threat to ships, yet some ships wreck in sea states characterized by 
relatively low wave heights and high wave steepness (Toffoli et al., 2005).

A sea state with a narrow wave spectrum was observed during several major ship accidents, including the Voyager accident (Bertotti and Cavaleri, 2008), the Suwa Maru incident (Tamura et al., 2009), the Louis Majesty accident (Cavaleri et al., 2012) and the Onomichi Maru incident (In et al., 2009; Waseda et al., 2014). Studies have assumed that the narrowed wave spectrum is primarily generated by the nonlinear coupling of swell and wind sea (or swell and swell) (Bertotti and Cavaleri, 2008; Tamura et al., 2009; Cavaleri et al., 2012; Waseda et al., 2012). During such wave couplings, the wave energy from one wave system (wind sea or swell) is enhanced and transferred to the other wave system (usually a swell) (Tamura et al., 2009; Waseda et al., 2014). As a result, the wave energy transformation produces a steep swell, with a high wave energy and extreme wave height (Bertotti and Cavaleri, 2008).

The angle of obliquity between two waves is another important condition involved in the interaction of wave systems. The traveling angles associated with ship accidents have varied from $10^{\circ}$ (Onorato et al., 2010) to $60^{\circ}$ (Tamura et al., 2009). The features noted above emerge individually or simultaneously during ship accidents or rare extreme sea states when swells and wind seas co-occur. Indeed, the cooccurrence of wind seas and swells can lead to dangerous seas, as demonstrated by the parametric rolling experienced by the German research vessel Polarstern (Bruns et al., 2011) despite the absence of extreme wave heights.

In previous studies of ship accidents, researchers focused on only one severe accident when discussing the sea state dynamics in detail or based their studies on ship accident data to perform statistical analyses of classical sea state parameters (e.g., $H_{\mathrm{S}}$ and $T$ ). To thoroughly investigate sea state parameters, we collected information on a large number of ship accidents and created a database for analysis. Additionally, we discussed the parameters in both wind sea and swell conditions. Statistical analyses were performed on data obtained from the International Maritime Organization (IMO). The data include 10 years of ship accidents (2001-2010) and 755 cases caused by bad weather or heavy seas. Because swells with large wave energies can represent a threat to maritime activities, 58 cases in which swells were reported as an important factor in the ship accident were selected. The detailed information discussed above is presented in Sect. 2. Following an overview of the ship accidents (Sect. 3), an analysis of the swell-related sea state conditions for these ship accident cases is presented in Sect. 4. In Sect. 5, two cases are illustrated to demonstrate the dynamic processes that ensue when wind sea and swell conditions occur during ship accidents. Finally, a summary and discussion are provided (Sect. 6).

\section{Data and methods}

\subsection{Ship accident database}

A 10-year (2001-2010) ship accident dataset was gathered from the Marine Casualties and Incidents Reports issued by the IMO. The dataset includes 3648 ship accidents, and each accident in the report includes the occurrence information, such as the accident time and coordinates, initial event, summary, casualty type and ship type. Since the primary information used in this study includes the accident time and coordinates, events that failed to record these details were excluded, and 1561 cases with exact geographical locations remained in the dataset.

According to the description of initial events, which provides clues regarding the accident causes recorded in the reports, those 1561 valid cases cover different kinds of cases triggered by natural factors and human factors. Because we focus on the events that occurred in natural weather-related conditions, cases with descriptions such as fire or explosion, improper operations and lost persons were eliminated from the 1561 cases, while cases with keywords such as strong wind, gale or cyclone or heavy seas or rough waves were kept. Although the proximal human factors resulting in ship accidents recorded in the IMO reports may have been indirectly related to dangerous seas or heavy weather, e.g., improper operations by crews, it would be exceedingly difficult to analyze the original factors case by case. Thus, distinguishing among trigger factors based on initial event keywords represents an optimal way of filtering the dataset. After this filtering, 755 weather-related accidents were obtained for the further analysis. An overview of these 755 cases is presented in Sect. 3.

Furthermore, this study focuses on the cases that occurred in swell-related sea states. After examining all the summaries of the 755 cases, we retained 58 cases with clear descriptions of the swell motion during the ship accidents for the analysis of the swell-related sea states. A detailed analysis is presented in Sect. 4.

\subsection{Numerical wave model data}

The ERA-20C numerical wave model data were obtained from the European Center for Medium-Range Weather Forecasts (ECMWF). The ECMWF uses atmosphere, land, surface and ocean wave models and data to reanalyze the weather conditions during the last century. The ERA-20C products describe the spatiotemporal evolution of ocean waves for 25 frequencies and 12 directions. The accuracy is improved by validation with ERA-40 data and operational archive results. Compared to the ERA-Interim dataset (12 h), ERA-20C has longer reanalysis coverage $(24 \mathrm{~h})$ for singlepoint data (Poli et al., 2013). The Ocean Wave Daily data in the ERA-20C dataset are available from 1900 to 2010 every $3 \mathrm{~h}$ at a grid size of $0.125^{\circ}$. The data provide 33 reanalyzed 


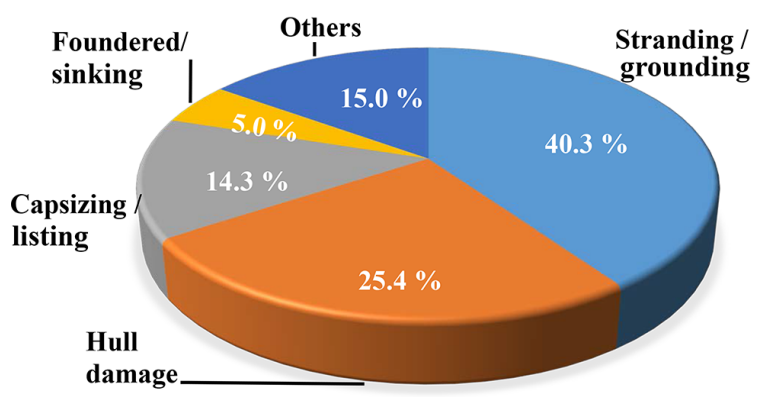

(a) Classification based on initial events

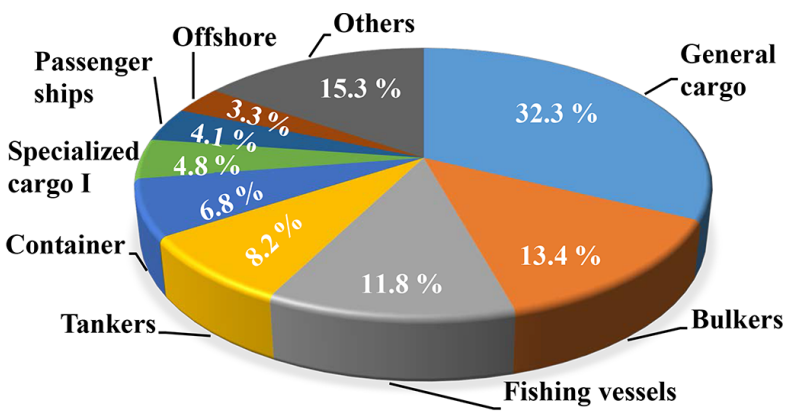

(b) Classification based on ship types

Figure 1. Classification of the 755 weather-related ship accidents based on initial events (a) and ship type (b). The accidents were recorded in the International Maritime Organization (IMO) database.

ocean wave parameters, and separate entries are included for swell and wind sea.

\section{Overview of ship accidents}

In the ship accident dataset, 755 weather-related cases were distinguished and discussed in Sect. 2. Hereafter, we provide an overview of these 755 cases in terms of the initial events, ship types and spatial distribution. The initial event in the IMO reports describes the triggering behaviors of each accident. Based on these records, five types of initial events were selected for classification, which are stranding/grounding, hull damage, others, capsizing/listing and foundering/sinking, sorted from the largest proportion to the smallest (Fig. 1a). The initial event labeled others in the classification includes report keywords such as "machinery damage due to heavy weather", "cargoes shifting due to rough seas" and "fatalities in heavy weather conditions", which are all related to bad weather. Note that the classification shown in Fig. 1a is based not on a detailed trigger factor but on a general result. For instance, when the ship accidents are classified as stranding/grounding or foundering/sinking, the vessels may have suffered from various types of dangerous seas or bad weather, including parametric rolling, extreme slamming, bending and torsional stresses and/or green water on deck, all of which all can reduce a ship's stability and consequently cause stranding/grounding or sinking.

Different types of ships respond differently when they encounter potentially dangerous sea conditions because of their different structures and functions. Among the 755 cases, general cargo vessel types experienced the highest proportion of accidents $(32.3 \%)$ in rough weather and severe sea states, followed by bulkers and fishing vessels. Collectively, these data highlight the types of ships that may require more attention during shipping activities (Fig. 1b).

Figure 2 presents the spatial distribution of the 755 cases in terms of occurrence density. To construct the ship accident density graph, the research area was divided into
188325 raster cells with a cell size of $50 \mathrm{~km} \times 50 \mathrm{~km}$. Then, a circle area with a radius of $500 \mathrm{~km}$ was defined as the region around each cell center. The number of ship accidents that fell within each region was summed and divided by the area of the region, which provided the ship accident density. Additionally, 58 ship accidents that occurred in swell sea states have been superimposed as blue dots. The areas of deeper colors in the map reflect a higher density of ship accidents. Clearly, these accidents are densely distributed in the North Atlantic Ocean, the North Indian Ocean and the west Pacific Ocean, which represent areas that coincide with the major shipping routes of Asian, European and North American countries.

Figure 2 shows that few accidents occurred in the open sea, although this result may have been related to the limited data recorded in the IMO database on severe open sea accidents that occurred from 2001 to 2010.

\section{Analysis of the sea state during ship accidents}

As discussed in the Introduction, the co-occurrence of wind sea and swell conditions is considered a potential causal factor that leads to dangerous sea states for ships. In this section, we focus on 58 swell-related cases to discuss the sea state characteristics associated with wind sea and swell conditions. The sea states are described by three parameters: significant wave height, wave period and wave direction. Sea wind does have a significant impact on shipping safety, and in many cases the high waves induced by wind can cause serious ship casualties. However, in this study, we focus on the impacts of sea state on shipping safety when both wind sea and swell are present. Swells are long waves propagating far from their generation sources and are therefore no longer affected by the original sea wind. Consequently, in this study, the relation between sea wind and ship accidents was not considered. 


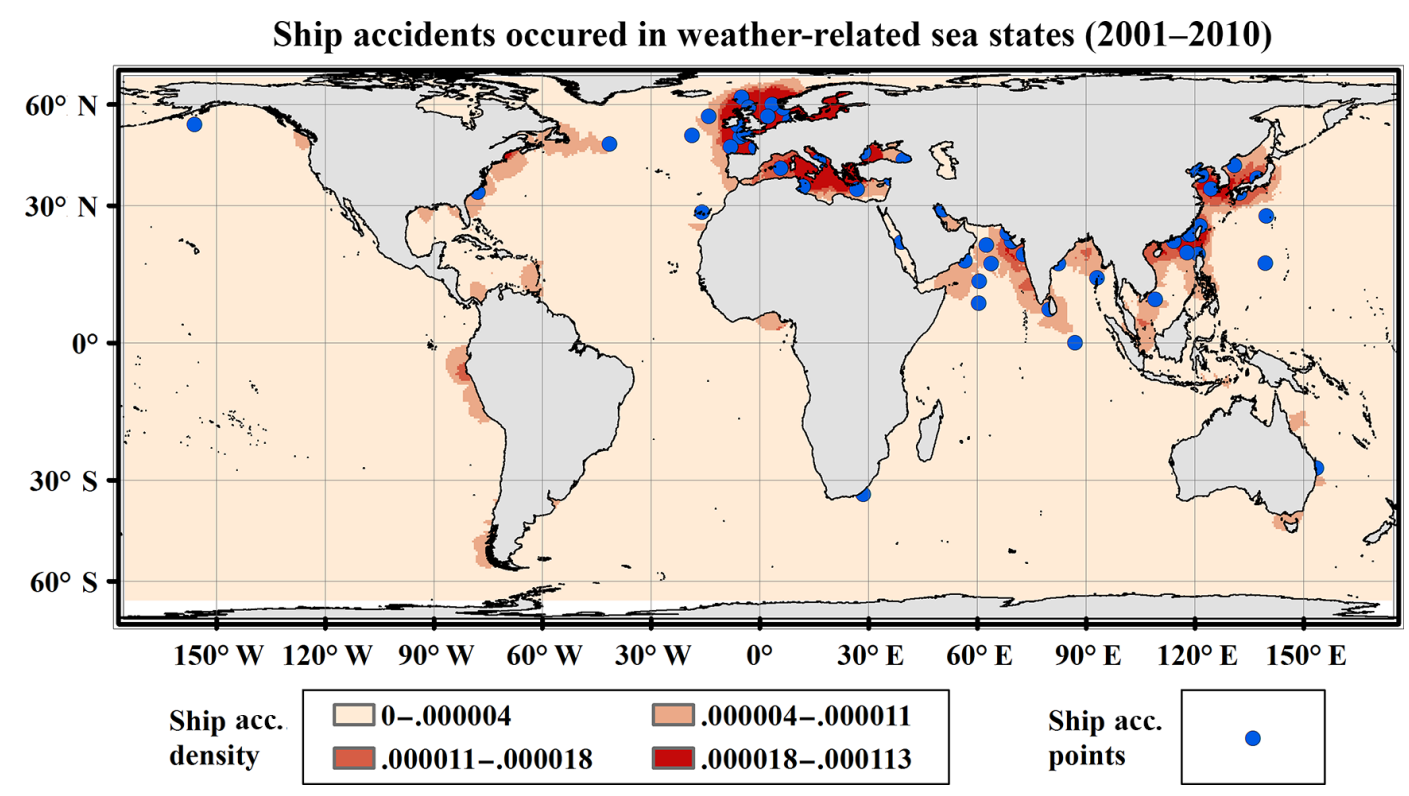

Figure 2. Geographical distribution of the ship accident density according to the 755 weather-related cases. The superimposed blue dots indicate the ship accidents ( 58 cases) that occurred in a swell sea state.

\subsection{Significant wave height}

In terms of swell-related cases, both the total sea wave height and swell wave height $\left(H_{\mathrm{sw}}\right)$ were analyzed. Moreover, the percentage of swell wave energy relative to the total sea energy was used in the analysis. Figure 3a shows the distribution of these values. The bar chart indicates that almost half of the cases occurred in an $H_{\mathrm{s}}$ range of $0-3 \mathrm{~m}$, which is not high enough to warrant a rough-sea warning. However, the proportion of the swell wave energy (i.e., the line in the graph) within this range is greater than $50 \%$; thus, when ships sail in relatively low sea states, the increased contribution of swells may lead to dangerous sea states that threaten shipping safety. Along with an increase in $H_{\mathrm{s}}$, the proportion of swell wave energy relative to the total sea energy remains at approximately $30 \%$, which reflects the increasing contribution of wind sea to worsening sea conditions when $H_{\mathrm{s}}$ is greater than $3 \mathrm{~m}$. In general, almost half of the swell-related cases occurred at $H_{\mathrm{s}}$ values smaller than $3 \mathrm{~m}$, which suggests that high wave height is not the only critical factor that triggers ship accidents. Indeed, other parameters may also play pivotal causal roles in these accidents. Therefore, additional wave parameters, including the wave period and wave direction, are subsequently examined for these accidents.

\subsection{Mean wave period}

Figure $3 b$ depicts the relationship between the occurrence of specific ship accidents and wave period differences (bar charts) between swells and wind sea ( $\Delta T$, i.e., the mean period of the swell minus the mean period of the wind sea). Furthermore, the mean wave period of the total sea ( $T$, solid line) is also plotted in the graph. Approximately two-thirds of the cases occurred in sea states where $\Delta T$ was less than $3 \mathrm{~s}$ and the value of $T$ approached $7 \mathrm{~s}$, which represents a close wave period for swell and wind sea conditions in most cases. In other cases, the value of $T$ was larger than $8 \mathrm{~s}$ when $\Delta T$ was larger than $3 \mathrm{~s}$. On the whole, an upward trend can be observed with an increase in $\Delta T$, except for a slight fluctuation between 4 and $5 \mathrm{~s}$. Overall, a close mean wave period $(\Delta T<3 \mathrm{~s}$ ) between swell and wind sea in a co-occurring sea state is an important factor for shipping accidents.

\subsection{Mean wave direction}

As noted in the Introduction, previous theoretical studies and ship accident analyses have indicated that crossing sea states (particularly crossing swell and wind sea states) may induce high waves and generate dangerous sea conditions. To investigate this issue further, the mean wave direction differences between the swell and wind sea $(\Delta \mathrm{D}$, i.e., the absolute value of the mean swell direction minus the mean wind sea direction) for all the swell-related ship accidents have been analyzed. Approximately half of the cases $(55 \%)$ exhibited $\Delta \mathrm{D}$ values less than $30^{\circ}$ (Fig. 3c), and the values of $\Delta T$ (indicated by the solid line superimposed on the bars) within this range were approximately $3 \mathrm{~s}$ before decreasing to $1.8 \mathrm{~s}$ at $\Delta \mathrm{D}$ values ranging from 30 to $40^{\circ}$. During swell and wind sea interactions, the rate of change in swell energy under the influence of wind sea energy (Tamura et al., 2009) reaches a maximum at approximately $40^{\circ}$ (Masson, 1993). The $\Delta \mathrm{D}$ range of 30 to $40^{\circ}$ for the lowest value of $\Delta T(1.8 \mathrm{~s})$ demonstrates strong coupling between two waves. However, $45 \%$ of the accidents were associated with $\Delta \mathrm{D}$ values larger than 

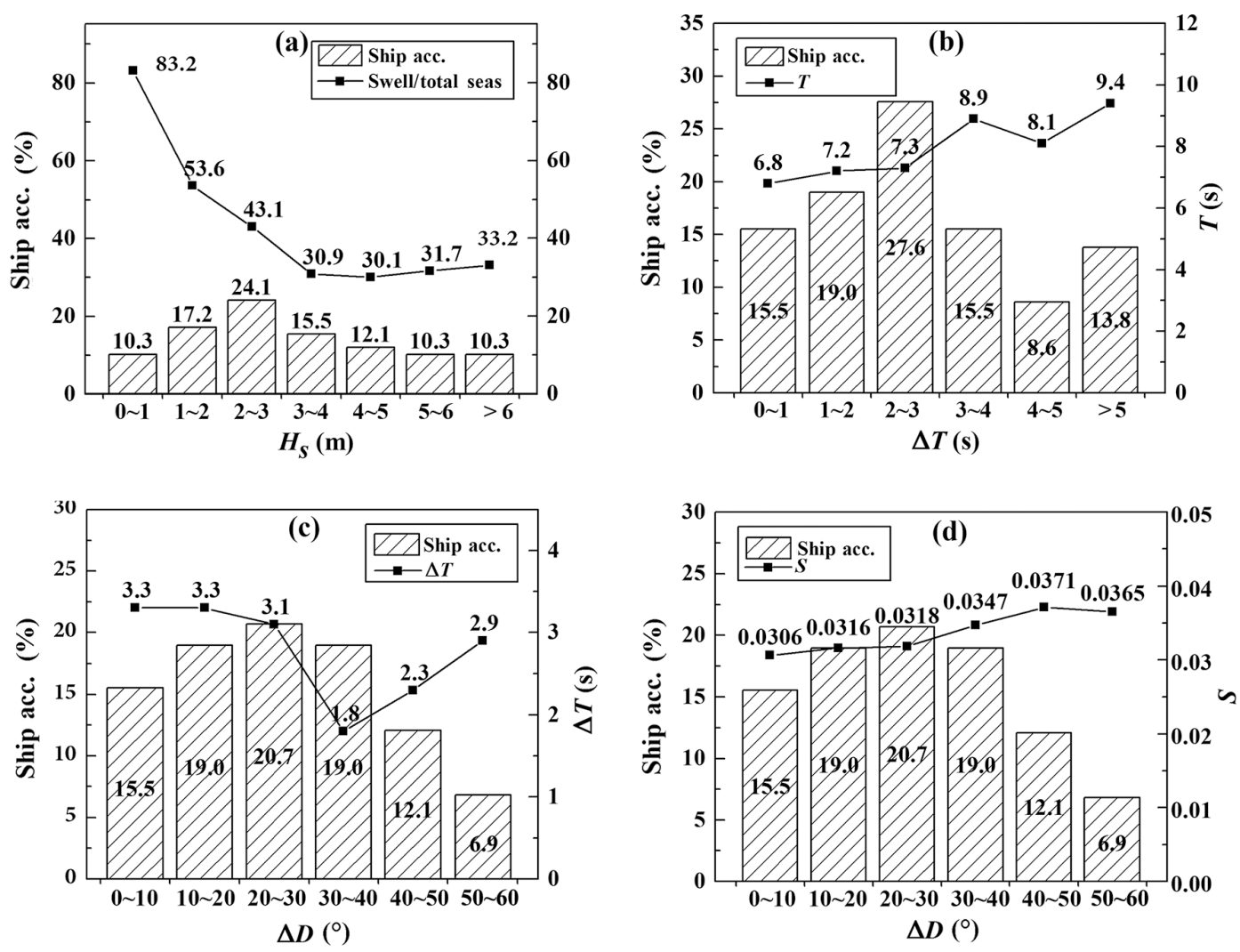

Figure 3. Incidence rate of ship accidents: (a) at different significant wave heights $\left(\mathrm{H}_{s}\right.$, bar chart) and the proportional change in swell energy in the total sea (polygonal line); (b) with wave period differences $(\Delta T$, bar chart) and the mean wave period $(T$, polygonal line); (c) with wave direction differences $(\Delta \mathrm{D})$ and $\Delta T$; and (d) with $\Delta \mathrm{D}$ and the value of the wave steepness of the total sea $(S)$.

$30^{\circ}$. An angle of $30^{\circ}$ appears to be a critical point for ship accidents because a rising trend in the $\Delta T$ line begins at this point. As the angle increases, the $\Delta T$ values decrease to below $3 \mathrm{~s}$, and the sea state can be more easily transformed into a crossing sea state (Li, 2016; Onorato et al., 2010), which could pose a risk for ships.

Figure 3d is identical to Fig. 3c except that the wave steepness of the total sea $(S)$ has been added to the bar chart. In the present study, the wave steepness of the total sea is calculated via $S=2 \pi H_{\mathrm{s}} / g T^{2}$. Along with an increase in $\Delta \mathrm{D}$, a rising trend in wave steepness can be observed, although a slight fluctuation appears from $40-50^{\circ}$. Wave steepness appears to be positively correlated with $\Delta \mathrm{D}$, particularly when $\Delta \mathrm{D}$ of approximately $50^{\circ}$. This condition is associated with a crossing sea state with a close wave period. Overall, large direction angle and wave steepness values appear to generate dangerous sea state conditions.

\section{Sea states of typical cases}

Based on the statistical analysis of the sea state characteristics presented above, we preliminarily conclude that close wave periods and oblique angles between co-occurring wind sea and swell conditions play important causal roles in ship accidents. In this section, two cases are presented to reveal the dynamic processes underlying co-occurring wind sea and swell conditions during ship accidents. One case occurred in a relatively low sea state, while the other case occurred in a high sea state.

The first ship accident case occurred at approximately 20:30 UTC on 24 February 2009. The Korean tug Chong jin capsized at $34^{\circ} 8^{\prime} \mathrm{N}, 124^{\circ} 131^{\prime} \mathrm{E}$. To thoroughly investigate the possible cause of this accident, the sea state is analyzed in detail. Figure 4 shows the time series of the sea state and sea surface wind at the accident location over $24 \mathrm{~h}$. At the top of the graph, wind vanes and numbers represent the sea surface wind direction and wind speed. The lines in the middle of graph represent significant wave heights of the swell (blue), wind sea (green) and total sea (grey). The mean wave period of the swell and wind sea are annotated in the same colors as the wave height. The wave directions of the swell and wind sea are also presented at the bottom of the graph.

At 12:00 UTC on 24 February, approximately $8 \mathrm{~h}$ before the ship accident, the sea was low with an $H_{\mathrm{s}}$ of $0.7 \mathrm{~m}$. The dominant wave was a swell as it moved to the northwest, and the wind sea was fairly mild. At 15:00 UTC, the wind sea began to develop rapidly due to sudden changes in the 


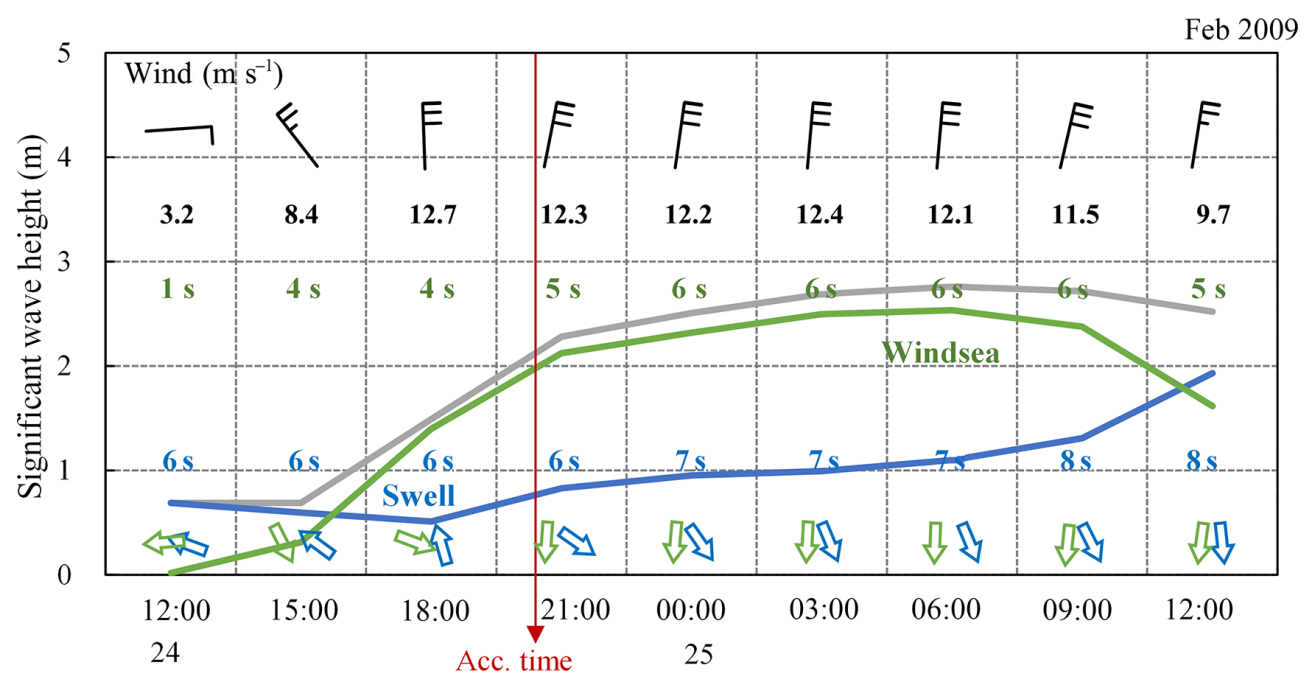

Figure 4. Time series of sea surface wind and sea state at the ship accident location over $24 \mathrm{~h}$ for the case occurred at 20:30 UTC on 24 February 2009. At the top of the figure, wind vanes and numbers indicate wind direction and wind speed at the accident location. Three polylines that represent the significant wave height of total sea, wind sea and swell, respectively, in grey, green and blue. The numbers in green and blue are the mean wave period of wind sea and swell. At the bottom of the figure, the arrows that in green and blue indicate the mean wave direction of wind sea and swell, respectively.

wind field (the wind direction changed from east to northwest, and the wind speed increased from 3.2 to $8.4 \mathrm{~m} \mathrm{~s}^{-1}$ ). Along with the continual growth of the wind sea, the difference between $T_{\mathrm{sw}}$ and $T_{\mathrm{ws}}$ decreased. The wave directions of the wind sea and swell at this moment were almost opposite. Soon thereafter, at 18:00 UTC, the wind speed rose continuously and reached $12.7 \mathrm{~m} \mathrm{~s}^{-1}$, while the wind direction tended to the north. The $H_{\mathrm{ws}}$ reached $1.4 \mathrm{~m}$, while the $H_{\mathrm{sw}}$ was still less than $1 \mathrm{~m}$. When the accident occurred (close to 21:00 UTC), the swell direction was distinctly different from that at 18:00 UTC, as it had shifted from southeasterly to northwesterly. As the sea became rough, both $H_{\mathrm{s}}$ and $H_{\mathrm{ws}}$ increased rapidly by $2 \mathrm{~m}$. Similar growth occurred in the wave periods, specifically, from 5.7 to $6.2 \mathrm{~s}$ for the swell and from 4.3 to $5.4 \mathrm{~s}$ for the wind sea. As the wave period of the wind sea became close to the swell, the difference between them $(\Delta T)$ decreased to $1 \mathrm{~s}$.

Figure 4 shows variations in the sea state at the accident location, while sea state in the vicinity of the accident is presented in Fig. 5. The diagrams in the first column show the wave model results at 18:00 UTC, $3 \mathrm{~h}$ before the accident, whereas the second column shows the results at 21:00 UTC, close to the accident occurrence time. From top to bottom, the sea state parameters are $H_{\mathrm{s}}, \Delta T$ and $\Delta \mathrm{D}$. Within $3 \mathrm{~h}$ of the ship accident occurrence, the $H_{\mathrm{s}}$ increased slightly by approximately $0.5 \mathrm{~m}$ across a large area proximal to the accident location. Due to the growth of the wind sea forced by local wind (refer to Fig. 6), the wave period difference $\Delta T$ decreased by approximately $2 \mathrm{~s}$ in the area. The most distinct variation in sea state in the area is $\Delta \mathrm{D}$. At 18:00 UTC, the swell direction in the area was southeasterly, propagating from other areas to the ship accident location. However, after $3 \mathrm{~h}$, the swell direction changed to northwesterly, the opposite of the direction $3 \mathrm{~h}$ before. Based on the wave direction of the wind sea in the area, we find that the northwesterly swell system (at 21:00 UTC) likely transformed from a fully developed local wind sea after the wind direction turned to the north at 15:00 UTC. Consequently, $\Delta D$ narrowed greatly from 187 to $59^{\circ}$ at $21: 00 \mathrm{UTC}$, further decreasing to $30^{\circ}$ at 03:00 UTC on 25 February.

The change in the wind is considered a key factor in this accident. The turning point appeared at 15:00 UTC on the 24 February, when the sea wind changed significantly in terms of both magnitude and direction. Afterwards, the continuous force of the sea wind induced the growth of the wind sea. The "old" wind sea was transformed into a young swell, which led to a marked decrease in $\Delta \mathrm{D}$. The closer wave period and narrower direction angle between the wind sea and the swell produced a resonance effect. Some experimental studies suggest that a swell with the same direction as the wind will play a role in suppressing the growth of a wind sea (Philips and Banner, 1974; DoneJan, 1987). As the swell direction tends to be the same as the wind direction, the development of a wind sea is suppressed. Meanwhile, the lower $\Delta \mathrm{D}$ and $\Delta T$ provided conditions for wave energy transformations from the wind sea to the swell (Masson, 1993). Closer wave periods and narrower wave spectrum provide ideal conditions for the transformation of wave energy, and the resulting energy-enhanced swell represents a great threat to shipping safety.

Based on the analysis presented above, we found that the crossing sea state of swell and wind sea may have triggered 
(a)

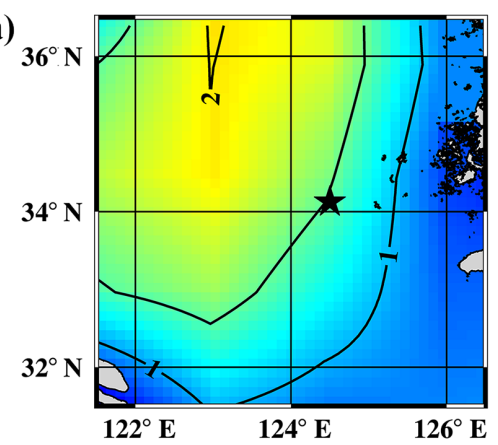

(c)

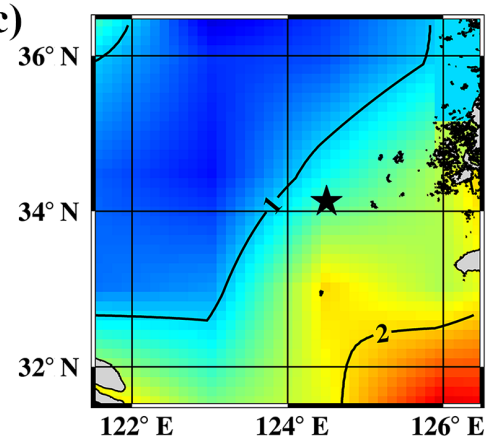

(e)

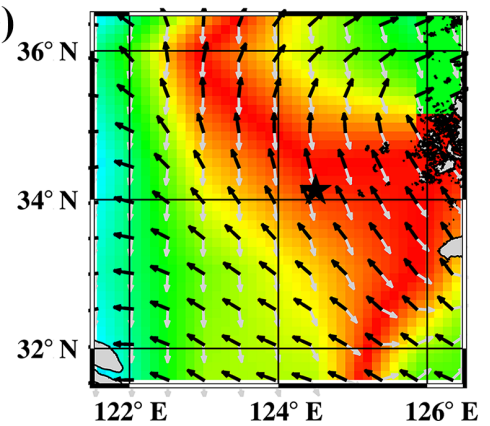

(b)

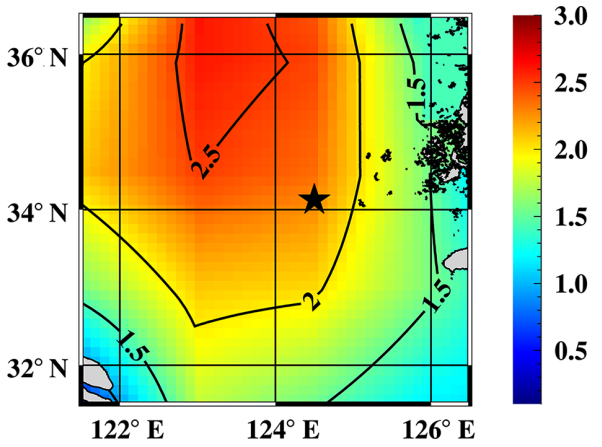

(d)

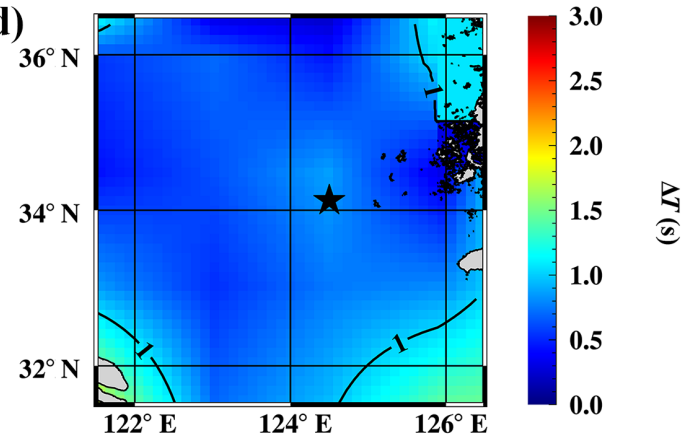

(f)

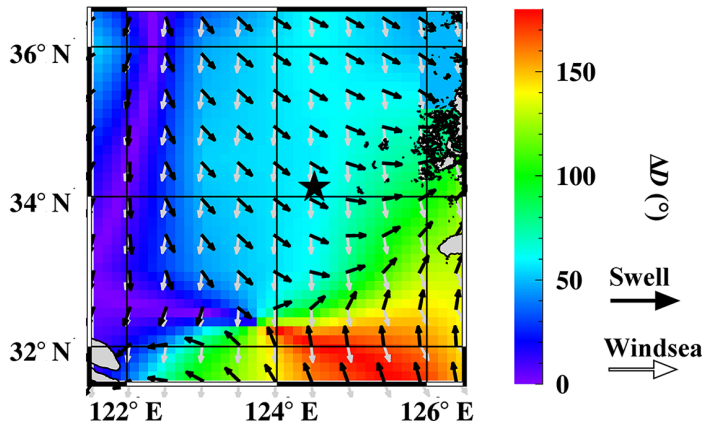

Figure 5. The sea state in the vicinity of the case that occurred on 24 February 2009. Panels (a), (c), (e) and (b), (d), (f) are the model results at 18:00 and 21:00 UTC, respectively; panels (a) and (b) are $H_{\mathrm{s}}$, (c) and (d) are $\Delta T$ and (e) and (f) are $\Delta \mathrm{D}$. The accident location is marked with a black star. Arrows in the plots of the third row represent the wave directions of the swell (black) and wind sea (light grey).

(a)

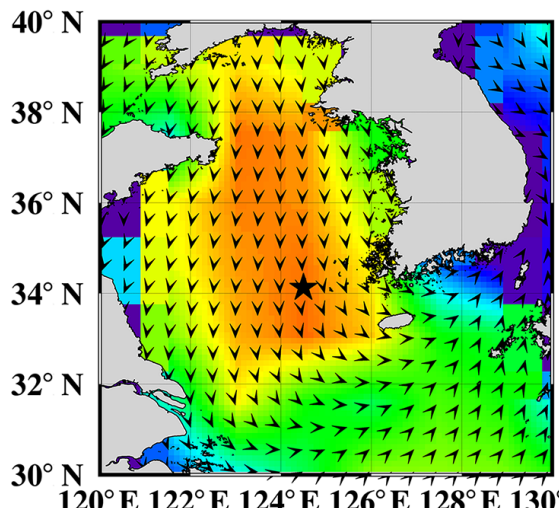

(b) 20090224 21:00 UTC

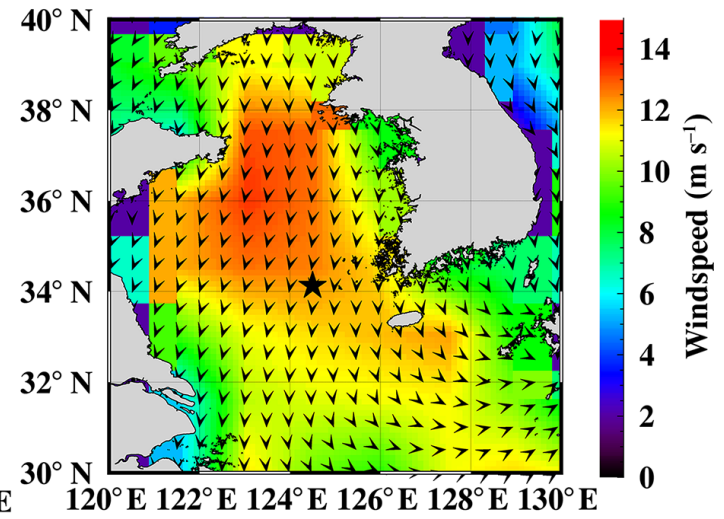

Figure 6. The sea surface wind fields at 18:00 (a) and 21:00 UTC (b) of the first case that occurred at 20:30 UTC on 24 February 2009. The accident location is marked with a black star. The arrows represent the sea surface wind directions. 


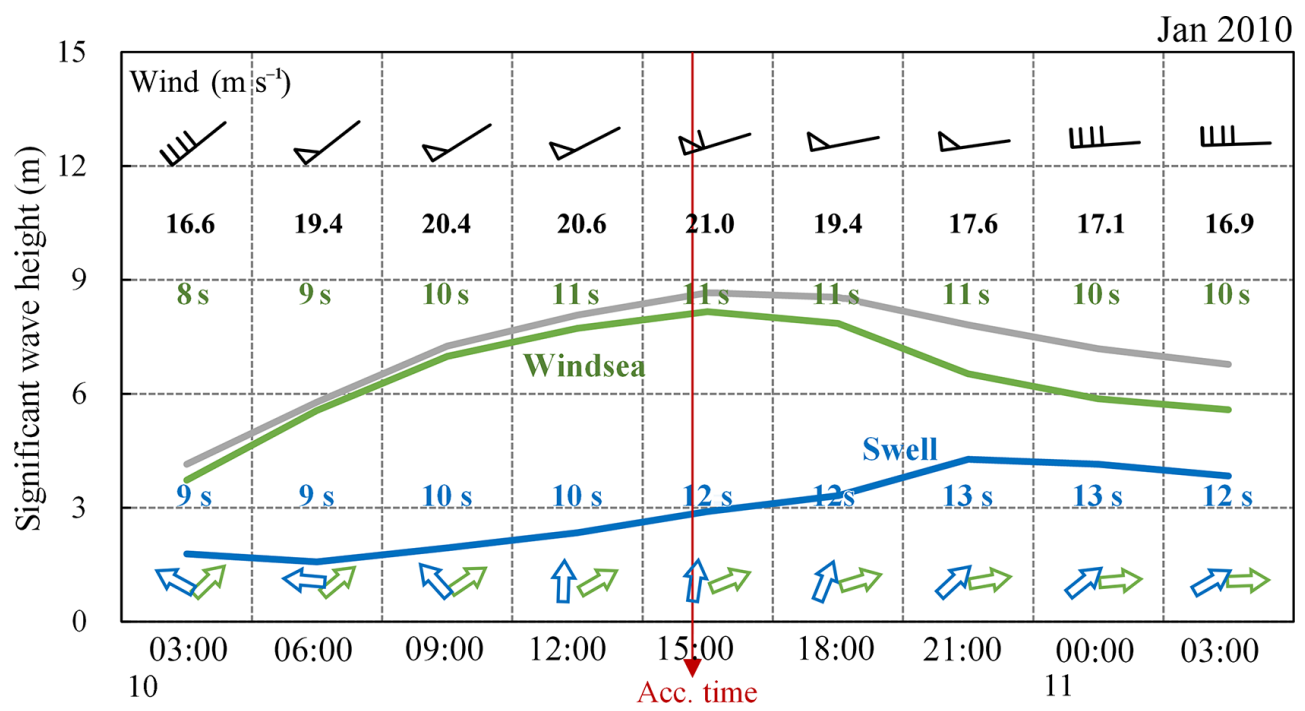

Figure 7. Time series of sea surface wind and sea state at the ship accident location over $24 \mathrm{~h}$ for the case that occurred at $14: 45 \mathrm{UTC}$ on 10 January 2010. The lines, symbols and numbers in the figure have the same meanings as those presented in Fig. 4.

the accident. Moreover, the swell that had a significant impact on the ship accident was transferred from the local wind sea instead of the "old" one that propagated from a distant storm. In the numerical wave modeling, discrimination of "swell" and "wind sea" occurs in the post-processing step through wave spectral partitioning. This spectral partitioning arbitrarily divides the two-dimensional wave spectrum into wind sea and swell components (Gerling, 1992; Hanson and Phillips, 2000) based on some criteria, and the integrated wave parameters of the corresponding wind sea and swell are subsequently derived. These swell and wind sea values are useful for depicting the trend of a sea state and can significantly contribute to many applications, such as forecast and analysis of surface wave conditions in shipping lanes and coastal areas, as in the statistical analysis and the case study presented above. However, spectral partitioning may have trouble distinguishing among the essential attributes of a wave field when both wind sea and swell or multiple swell systems are present (Hanson and Phillips, 2000).

In the second case, a bulk carrier with a gross tonnage of 36546 sailed from Davant, United States, to Hamburg, Germany, on 10 January 2010 and at 14:45 UTC encountered extremely poor weather, with westerly winds of more than $20 \mathrm{~m} \mathrm{~s}^{-1}$ and southwest waves of more than $9 \mathrm{~m}$. As a result, the ship was seriously damaged at $46^{\circ} 14^{\prime} \mathrm{N}, 41^{\circ} 29^{\prime} \mathrm{W}$. The time series of the sea surface wind and sea state over $24 \mathrm{~h}$ for this case are presented in Fig. 7. The lines, symbols and numbers in the figure have the same meanings as those presented in Fig. 4.

Based on the sea surface wind field on 10 and 11 January over a large area in the vicinity of the ship accident (not shown here), the area was experiencing an extratropical cyclone. The $H_{\mathrm{s}}$ (over $8 \mathrm{~m}$ ) and sea surface wind speed (higher than $20 \mathrm{~m} \mathrm{~s}^{-1}$ ) presented in Figs. 7 and 8 also reveal the bad weather situation when the ship accident occurred. From 03:00 UTC until the approximate time of the ship accident, the wind sea grew under the force of the continuously increasing sea surface wind speed, as evidenced by the increases in $H_{\mathrm{ws}}$ and $T_{\mathrm{ws}}$. The time at which the ship accident occurred, i.e., approximately 15:00 UTC, likely corresponds to a turning point in the wind sea growth. Before then, the $H_{\mathrm{ws}}$ continuously increased from $3.7 \mathrm{~m}$ at 03:00 UTC to $8.2 \mathrm{~m}$ at 15:00 UTC. Simultaneously, the $T_{\mathrm{ws}}$ increased from 8 to $11 \mathrm{~s}$. After the turning point, both the wave height and wave period of the wind sea started to decrease gradually. More interesting is the variation in the swell in the area. At the ship accident location, both $H_{\mathrm{sw}}$ and $T_{\mathrm{sw}}$ gradually increased from 03:00 UTC to 21:00 UTC on 10 January. However, the time series of the mean wave direction of swell shown in Fig. 7 suggests that the swell situation was very complicated. At 03:00 and 06:00 UTC on 10 January, the easterly swell was the dominant swell system. The mean wave direction of the swell subsequently gradually turned to southerly and southwesterly, leading to a decrease in the $\Delta \mathrm{D}$ from 107 (03:00 UTC) to 59 (15:00 UTC).

The sea state maps shown in Fig. 8 can better resolve the variations over the course of a few hours. The $H_{\mathrm{s}}$ graph clearly shows that the higher wave area increased in size within $3 \mathrm{~h}$. The $\Delta T$ map suggests that the swell and wind sea had a close mean wave period of less than $1 \mathrm{~s}$ in a large area surrounding the ship accident location. In fact, the $\Delta T$ derived from the time series presented in Fig. 7 suggests that it retained a quite small value of $0-1 \mathrm{~s}$ for approximately $15 \mathrm{~h}$. The $\Delta \mathrm{D}$ graphs show that at least two swell systems existed in the area, with one being southerly/southwesterly and the other being southeasterly. This situation led to a high $\Delta \mathrm{D}$ 
(a)

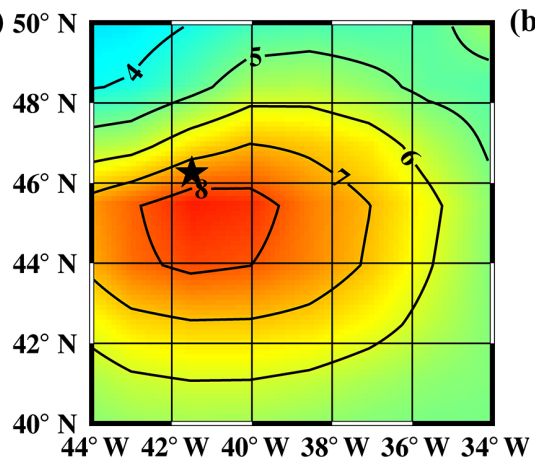

(c)

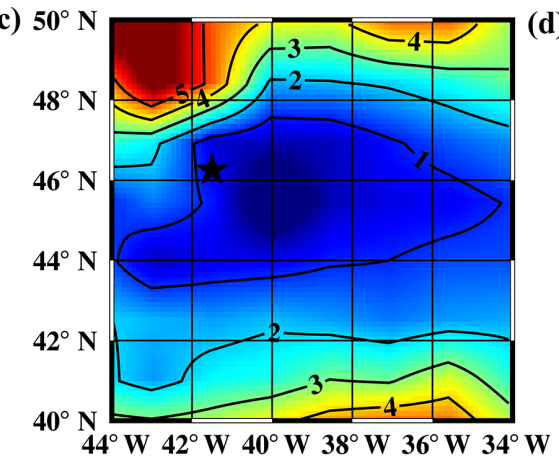

(b)

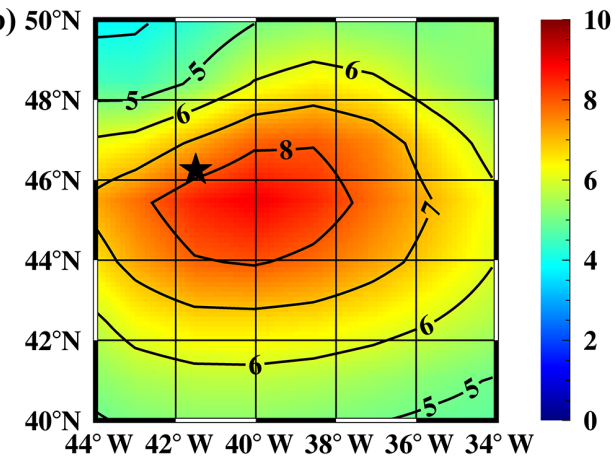

(d)

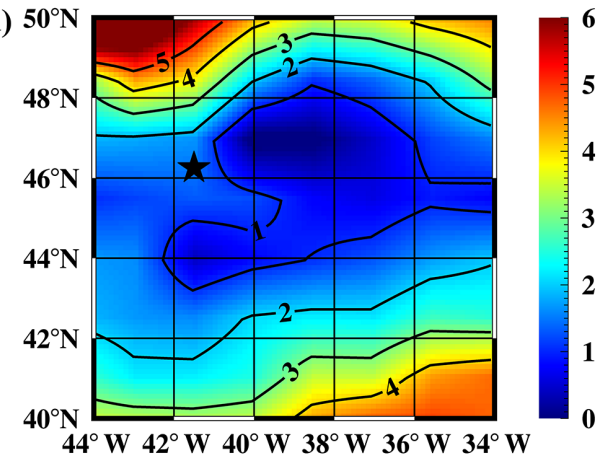

(e)

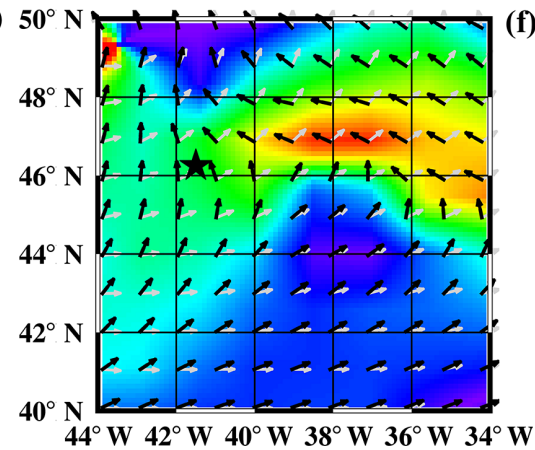

(f) 50

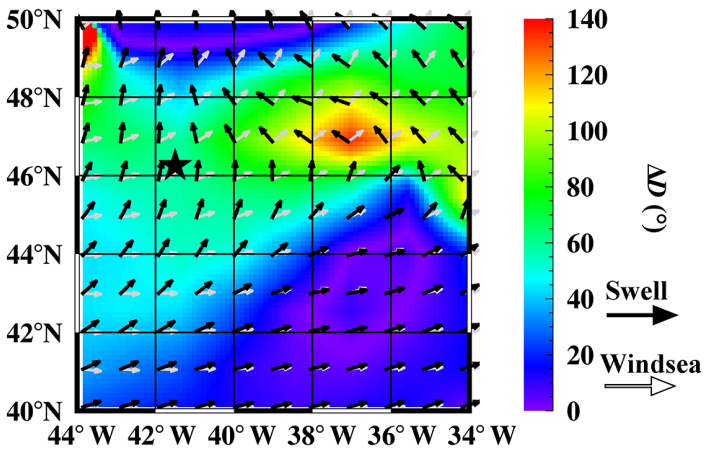

Figure 8. The sea state in the vicinity of the case that occurred on 10 January 2010. Panels (a), (c), (e) and (b), (d), (f) are the model results at 18:00 and 21:00 UTC, respectively; panels (a) and (b) show $H_{\mathrm{S}}$, (c) and (d) show $\Delta T$ and (e) and (f) show $\Delta \mathrm{D}$. The accident location is marked with a black star. Arrows in the plots of the third row represent the wave directions of the swell (black) and the wind sea (light grey).

area and a low $\Delta \mathrm{D}$ area. The boundary of the two $\Delta \mathrm{D}$ areas at $50-60^{\circ}$ was close to the accident area. Based on both Figs. 7 and 8 , the $\Delta \mathrm{D}$ was becoming smaller during the event, not only at the location of the ship accident but also across a large area. The time series of the swell wave direction may misleadingly suggest that the swell direction changed suddenly within a few hours. However, this was probably not the true situation. As stated in the analysis of the first case, discrimination of the swell and wind sea in the wave model post-processing step is an arbitrary process. The wave model product used in this study only provides one swell component, which cannot represent the complete swell state in a complicated situation. In this case, as mentioned above, the area was experiencing an extratropical cyclone that not only featured a rotational wind field but also moved in a certain direction, thereby generating swells propagating in various directions. Thus, multiple swell components might have coexisted in certain observation locations. However, spectral partitioning cannot resolve the complete swell components if only one (dominant) swell system was retained in the wave product, such as that used in this study. This situation can lead to misunderstanding data, suggesting that the swell direction changed suddenly.

Nevertheless, in the present case, large waves (higher than $8 \mathrm{~m}$ ) may have been a factor that threatened shipping activities. The additional causes of the accident were likely related to the decreasing wave period and wave direction changes that led to co-occurring wind sea and swell. 


\section{Summary and discussion}

The present study is motivated by a desire to thoroughly evaluate the sea state conditions during ship accidents. It aims to establish more accurate and effective maritime warning criteria and better understand the mechanisms underlying extreme waves. To this end, 10 years of ship accidents that occurred in rough weather or sea conditions were chosen from the IMO ship accident database and then analyzed.

Based on the selected 755 weather-related accident cases, an accident occurrence density map was generated. The ship accidents presented a dense distribution in the North Atlantic Ocean, the North Indian Ocean and the west Pacific Ocean because of the associated severe weather and sea state conditions, and the locations of these accidents coincided with major shipping routes. In terms of ship type in the casualty reports, the most frequent ships involved in these accidents included general cargo ships, bulkers and fishing vessels. Of the reported initial events, stranding/grounding and hull damage were the most prominent.

Strong winds and high waves can cause heavy sea states, which are indeed the primary risk factors for maritime activities. However, the potential dangers of swells with relatively low wave heights are generally underestimated. Notably, our analysis of the 58 swell-related accidents indicated that $52 \%$ of the cases occurred in relatively low sea state conditions with $H_{\mathrm{s}}$ values smaller than $3 \mathrm{~m}$ and that swells provided the dominant wave energy in these conditions. A further analysis of these accidents suggested that co-occurring wind sea and swells, especially when the differences in their mean wave periods and mean wave directions meet certain conditions, may lead to hazardous seas and pose a risk to shipping activities. Among the 58 swell-related ship accidents, approximately $62 \%$ of the cases have $\Delta T$ values of less than or equal to $3 \mathrm{~s}$. Interestingly, for all these cases, the averaged $\Delta T$ for different $\Delta \mathrm{D}$ is approximately $3 \mathrm{~s}$ and is smallest, i.e., $1.8 \mathrm{~s}$, when $\Delta \mathrm{D}$ is between 30 and $40^{\circ}$. When $\Delta \mathrm{D}$ is between 30 and $40^{\circ}$, the crossing sea state has a high potential of being composed of a wind sea and a swell transformed from the local wind sea, as was the situation in the first case. Overall, the statistical analysis reveals that $\Delta T$ values less than $3 \mathrm{~s}$ and $\Delta \mathrm{D}$ values smaller than $60^{\circ}$ are two important factors of crossing seas that can lead to wave interaction between the wind sea and the swells, consequently generating dangerous seas that threaten shipping safety. Therefore, this finding can potentially be used as a warning criterion in forecasts for shipping lanes.

According to the report records, many ship accidents have occurred in offshore areas yet few have occurred in open sea areas. Although the accuracy of the model data is fairly high, the coastline resolution used in the dataset is relatively coarse. As a result, a bias may exist in the offshore areas. Therefore, the diagrams shown in the statistical analysis appear to be somewhat noisy. However, even under the same sea state, different ship types should respond differently. This phenomenon may also lead to a variety of statistical results in a variety of situations. Nevertheless, the statistical results still reveal noteworthy characteristics of dangerous sea state conditions.

The sea states of the two case studies meet the general conditions of a possible occurrence of dangerous waves based on the statistical analysis, whereas they also presented different situations. In the first case, the overall sea state was relatively low, at $2.0-2.5 \mathrm{~m}$. However, the sea surface wind direction changed significantly approximately $6 \mathrm{~h}$ before the accident. The gradually enhanced northerly and northwesterly wind forced the growth and development of a wind sea, which later transformed into a swell. The "new" swell therefore had a markedly different direction from that present approximately $6 \mathrm{~h}$ before. The freshly generated swell and wind sea both had smaller $\Delta T$ and $\Delta \mathrm{D}$ values, producing favorable conditions for coupling between the swell and the wind sea and leading to possible generation of waves dangerous to ship safety. In the second case, the overall sea state was quite rough, with an $H_{\mathrm{s}}$ higher than $8 \mathrm{~m}$. Although the sea surface wind speed increased gradually before the accident occurred, the sea surface wind direction remained southwesterly. However, although $\Delta T$ remained quite small (approximately $1 \mathrm{~s}$ ) for more than $12 \mathrm{~h}, \Delta \mathrm{D}$ exhibited significant variation, decreasing from more than $100^{\circ}$ at $9 \mathrm{~h}$ before to approximately $60^{\circ}$ when the accident occurred. A plausible explanation is that the area was experiencing an extratropical cyclone, which had a rotational sea surface wind field and also moved continually. This cyclone therefore generated swells that propagated to multiple directions. Detailed analysis of the sea states associated with these two specific cases further demonstrates that both oblique wave directions and similar wave periods between the wind sea and the swell are two key factors of crossing seas that can lead to the generation of sea state dangerous to shipping safety.

Finally, ship safety could be improved if the major contributors to dangerous sea states are identified and monitored, especially along major shipping lanes. In future work, the use of multi-source data will undoubtedly provide a more complete description of these complex phenomena.

Data availability. The global ship accident database and the ERA20C Ocean Wave dataset were accessed from the IMO Global Integrated Shipping Information System (https://gisis.imo.org/Public/ Default.aspx/) and the ECMWF Public Datasets web portal (http:// apps.ecmwf.int/datasets/data/era20c-wave-daily/type=an/), respectively. The data are publicly accessible, readers can download the data by the website we provided.

Competing interests. The authors declare that they have no conflict of interest. 
Acknowledgements. This study was partially supported by grants from the National Natural Science Foundation of China (no. 41406198), Special Project of Chinese High-Resolution Earth Observation System (no. 41-Y20A14-9001-15/16), the Hainan Key S\&T Programme (no. ZDKJ2016015) and the "Pioneered Hundred Talents Program, Chinese Academy of Sciences".

Edited by: Thomas Glade

Reviewed by: Thomas Bruns and Weizeng Shao

\section{References}

Bertotti, L. and Cavaleri, L.: The predictability of the "Voyager" accident, Nat. Hazards Earth Syst. Sci., 8, 533-537, https://doi.org/10.5194/nhess-8-533-2008, 2008.

Bruns, T., Lehner, S., Li, X.-M., Hessner, K., and Rosenthal, W.: Analysis of an event of "Parametric Rolling" onboard RV "Polarstern" based on shipborne wave radar and satellite data, IEEE J. Ocean. Eng., 36, 364-372, 2011.

Cavaleri, L., Bertotti, L., Torrisi, L., Bitner-Gregersen, E., Serio, M., and Onorato, M.: Rogue waves in crossing seas: the Louis Majesty accident, J. Geophys. Res., 117, C00J10, https://doi.org/10.1029/2012JC007923, 2012.

DoneJan, M. A.: The effect of swell on the growth of wind waves, Johns Hopkins APL Tech Dig, 8, 18-23, 1987.

Faulkner, D.: Shipping safety: a matter of concern, in: ProceedingsInstitute of Marine Engineering Science and Technology Part B Journal of Marine Design and Operations, 5, 37-56, 2004.

Gerling, T. W.: Partitioning sequences and arrays of directional ocean wave spectra into component wave system, J. Atmos. Ocean. Tech., 9, 444-458, 1992.

Guedes, S. C., Bitner-Gregersen, E., and Antao, P.: Analysis of the frequency of ship accidents under severe North Atlantic weather conditions, in: Proceedings of the Conference on Design and Operation for Abnormal Conditions II, RINA, London, UK, 221230, 2001.
Hanson, J. L. and Phillips, O. M.: Automated analysis of ocean surface directional wave spectra, J. Atmos. Ocean. Tech., 18, 277293, 2001.

In, K., Waseda, T., Kiyomatsu, K., and Iyama, K.: Analysis of a marine accident and freak wave prediction with an operational wave model, in: Nineteenth International Offshore and Polar Engineering Conference. International Society of Offshore and Polar Engineers, 21-26, 2009.

Kharif, C., Pelinovsky, E., and Slunyaev, A.: Introduction, in: Rogue Waves in the Ocean, Springer, Berlin, Germany, 1-10, 2009.

Li, X.-M.: A new insight from space into swell propagation and crossing in the global oceans, Geophys. Res. Lett., 43, 52025209, 2016.

Masson, D.: On the nonlinear coupling between swell and wind waves, J. Phys. Oceanogr., 23, 1249-1258, 1993.

Onorato, M., Proment, D., and Toffoli, A.: Freak waves in crossing seas, Eur. Phys. J.-Spec. Top., 185, 45-55, 2010.

Philips, O. M. and Banner, M. L.: Wave breaking in the presence of wind drift and swell, J. Fluid Mech., 66, 625-640, 1974.

Poli, P., Hersbach, H., Tan, D. G. H., Dee, D. P., Thepaut, J-J., Simmons, A., Peubey, C., Laloyaux, P., Komori, T., Berrisford, P., Dragani, R., Trémolet, Y., Hólm, E. V., Bonavita, M., Isaksen, L., and Fisher, M.: ERA report series No. 14: The data assimilation system and initial performance evaluation of the ECMWF pilot reanalysis of the 20th-century assimilating surface observations only (ERA-20C), http://www.ecmwf.int/en/elibrary/11699, (last access: 26 September 2016), 2013.

Tamura, H., Waseda, T., and Miyazawa, Y.: Freakish sea state and swell-windsea coupling: numerical study of the Suwa-Maru incident, Geophys. Res. Lett., 36, L01607, https://doi.org/10.1029/2008GL036280, 2009.

Toffoli, A., Lefèvre, J. M., Bitner-Gregersen, E., and Monbaliu, J.: Towards the identification of warning criteria: analysis of a ship accident database, Appl. Ocean Res., 27, 281-291, 2005.

Waseda, T., Tamura, H., and Kinoshita, T.: Freakish sea index and sea states during ship accidents, J. Mar. Sci. Technol., 17, 305$314,2012$.

Waseda, T., In, K., Kiyomatsu, K., Tamura, H., Miyazawa, Y., and Iyama, K.: Predicting freakish sea state with an operational thirdgeneration wave model, Nat. Hazards Earth Syst. Sci., 14, 945957, https://doi.org/10.5194/nhess-14-945-2014, 2014. 